\title{
International Virtual Exchange Conference (IVEC) 2020 special issue: editorial
}

\section{Carine E. Ullom ${ }^{1}$ and Müge Satar ${ }^{2}$}

We are pleased to bring you this Special Issue of the Journal of Virtual Exchange, the second such volume to publish articles resulting from the International Virtual Exchange Conference (IVEC) $2020^{3}$. This special issue includes five research articles presented at IVEC 2020 (http://iveconference. org/2020-conference) and a panel discussion. Each manuscript underwent double-blind review, which was then followed by rigorous editing and revising. Their work represents the amazing diversity that is blossoming in the field of Virtual Exchange (VE) as practitioners, academic administrators, and researchers realise its potential as well as its inevitable challenges.

VE research presented in this special issue ranges from the study of the impact of VE on language learning (uptake) (Feng et al.) to a complex, three-way project with a focus on physical and digital accessibility (Oswal et al.). While Bartsch et al. describe their new framework that combines inquiry-based learning with digital storytelling in VE, Ganassin et al. share their findings regarding the underexplored area of staff (administrators and instructors) perceptions of the role of VE in Internationalisation at Home (IaH). In this same vein, Ruther et al. report on their work in an assessment-based approach to VE programme building. Findings from longitudinal studies are also presented, providing evidence that VE research as a discipline is maturing.

Before we present each article, here we offer a snapshot of the themes and highlights you will find in the research articles in this special issue (Table 1). The articles cover VE activity in eight countries in seven disciplines. The studies demonstrate different VE designs, including cross-disciplinary, longitudinal, and three-party designs. Several key VE themes run through the manuscripts, including accessibility, intercultural competence, internationalisation, and sustainable development.

1. Ottawa University, UNICollaboration, United States, carineullom@gmail.com; https://orcid.org/0000-0002-1755-0581

2. Newcastle University, United Kingdom; muge.satar@newcastle.ac.uk; https://orcid.org/0000-0002-2382-6740

3. Selected short papers from the IVEC2020 conference can be found here: Satar, M. (Ed.). (2021). Virtual exchange: towards digital equity in internationalisation. Research-publishing.net. https://doi.org/10.14705/rpnet.2021.53.9782490057955

How to cite this article: Ullom, C. E., \& Satar, M. (2021). International Virtual Exchange Conference (IVEC) 2020 special issue: editorial. Journal of Virtual Exchange, 4(SI-IVEC2020), i-v. https://doi.org/10.21827/jve.4.38202 


\section{Table 1. Themes emerging from the research articles in this special issue}

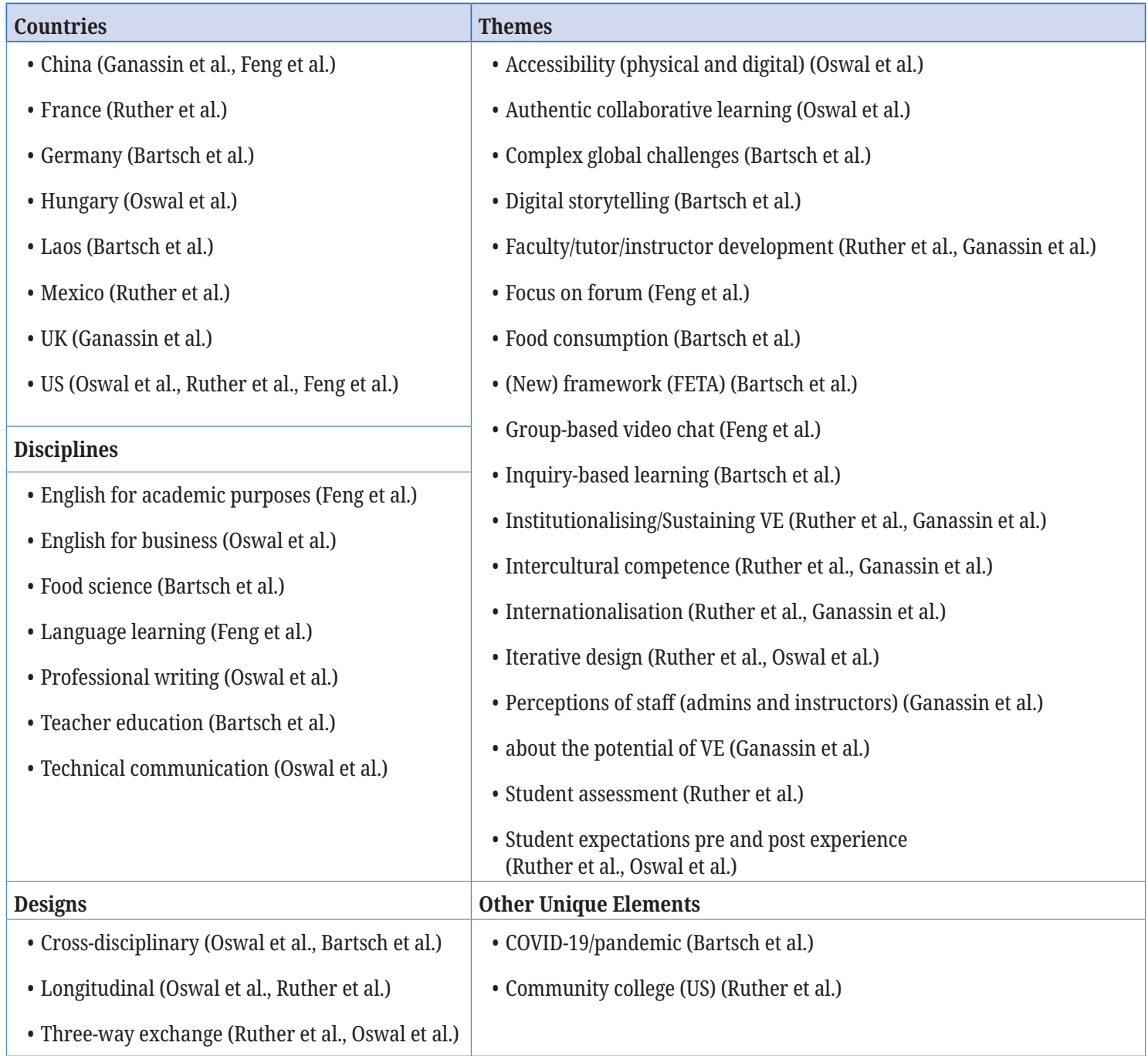

Oswal, Palmer, and Koris open this special issue with an interdisciplinary collaboration between three higher education institutions in the EU and the US. The authors investigate improvement in awareness of disability and accessibility in business contexts. Drawing on various data sources including surveys, videoconferencing meeting minutes, and instructor notes, Oswal and colleagues document positive outcomes in both learners' awareness of disabilities and their willingness to find solutions to issues related to disabilities. As the authors highlight in their conclusions, projects 
foregrounding issues of accessibility are key to ensuring "accessible education and information while contributing to the integration of people with disabilities in our global society”.

The second contribution in this issue explores feedback and uptake in online intercultural exchanges via videoconferencing. Feng, Shi, $\mathrm{Hu}$, and $\mathrm{Yu}$ investigate different types of feedback offered by American students to their Chinese peers during their exchanges in English, as well as factors that impact successful uptake. Following a thorough literature review on feedback practices during incidental focus on form and uptake, Feng and colleagues describe the research context. Analysing verbatim transcripts of recorded interactions, the authors found that recasts, clarification requests, and translations were the most frequently used feedback types, and peer repair was more likely to lead to successful uptake.

With their VE project between higher education students from Laos and Germany, Bartsch, Kittirath, Müller, and Youyabouth address a global challenge: food consumption and sustainability. As an interdisciplinary exchange, their students explored and reflected on their food consumption practices through inquiry-based learning and were then asked to represent their narratives and subjective meanings through digital storytelling. Bartsch et al. present both quantitative and qualitative evidence on students' development of consumer and sustainability competencies through the multimodal VE and argue for "a more systematic integration of VE into higher education” for global collaboration targeting global challenges.

In the next research article, Ruther, Jeffress, Shi, and Rabke offer an assessment-based approach to improve the quality of VE programmes through iterative VE design cycles. The authors report survey data collected over three years and explain how an external provider (Gazelle International) worked with a US community college supporting VE projects with France and Mexico. The external provider reviewed learning outcomes annually and offered teacher training and revisions to VE design. The findings indicate programme growth, improved learning outcomes, and institutionalisation of the VE programme. The authors encourage other institutions to explore their iterative, goal-oriented approach in their internationalisation efforts.

The final research article in this issue focuses on staff perspectives towards IaH through VE in China. Ganassin, Satar, and Regan investigate how internationalisation is perceived and the role of VE in this process within the context of Chinese higher education. The authors elicit administrator and teacher perspectives on the potential of VE for IaH through a series of training discussions. An interview with a Chinese instructor and their American VE partner sheds further light into a specific VE case between China and the USA. The authors report positive staff perspectives which suggest that VE can contribute to internationalisation and inclusive intercultural experiences in China. Their 
conclusions highlight techno-political challenges and the need to establish mutual understandings for successful and respectful VE partnerships.

We end the special issue with a panel contribution by Bali, Goes, and Patankar with the skilful moderation of Haug exploring the impacts of the COVID-19 pandemic on VE. The panel presentation was certainly one of the popular sessions at IVEC 2020 and we are pleased to include their video contribution as part of this volume. Bali, Goes, and Patankar each offer their expertise and observations in their countries depicting a vivid picture of the lived realities in Egypt, Brazil, and India. Their reflections span across issues of access, equality, well-being, and wider educational concepts. In this volume, we present the panel video along with selected highlights from their conversation.

Figure 1. A visualisation of the terms found in the abstracts of each research article
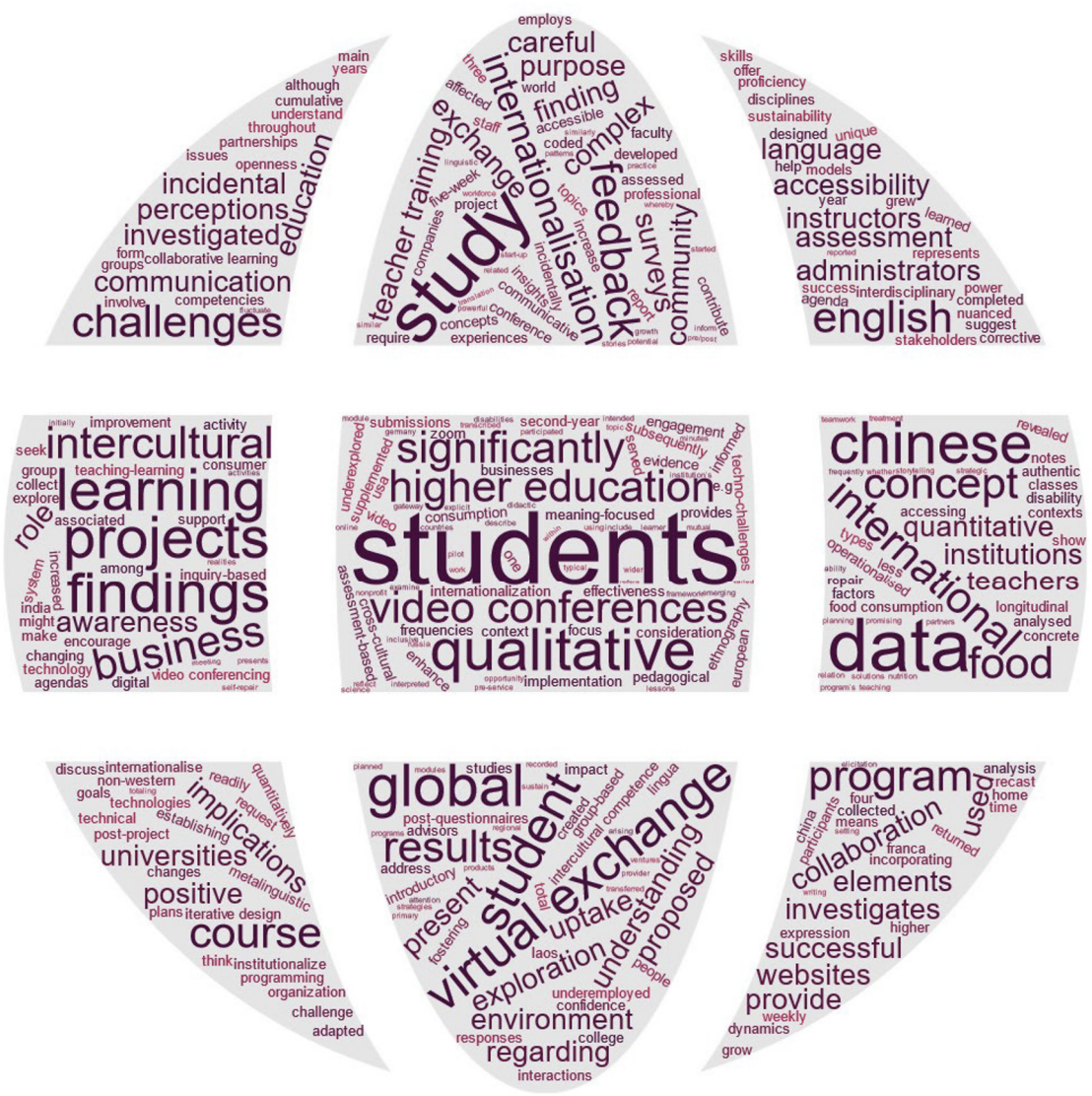
In closing, we offer a visualisation of the terms found in the abstracts of each research article (Figure 1). The globe as the 'container' for the representation of the work that we do seems apt. At first glance, it is clear that students are at the heart of the work of VE! We invite you to increase the page display size to uncover and explore the many concepts discussed in these works.

We hope you find value in these articles. It has been our pleasure serving as co-editors of this special issue. 


\section{Virtual Exchange?}

Published by University of Groningen Press | UGP, a not-for-profit press

Groningen, The Netherlands | UGP@rug.nl

(C) 2021 UNICollaboration (collective work)

(C) 2021 by Authors (individual work)

Journal of Virtual Exchange 2021

Special issue edited by Carine Ullom and Müge Satar

Publication date: 2021/12/22

Journal of Virtual Exchange (JVE) is an online, open-access, peer-reviewed journal aimed at practitioners and researchers in the field known variously as virtual exchange, telecollaboration, or online intercultural exchange. It is the official journal of UNICollaboration (https://www.UNICollaboration.org/), the international academic organisation dedicated to supporting and promoting telecollaboration and virtual exchange in higher-level education.

Rights. The whole volume is published under the Attribution-NonCommercial-NoDerivatives 4.0 International licence (CC BY-NCND 4.0); individual articles may have a different licence. Under the CC BY-NC-ND licence, the volume is freely available online for anybody to read, download, copy, and redistribute provided that the author(s), editorial team, and publisher are properly cited. Commercial use and derivative works are, however, not permitted.

Disclaimer. University of Groningen Press does not take any responsibility for the content of the pages written by the authors of this article. The authors have recognised that the work described was not published before, or that it was not under consideration for publication elsewhere. While the information in this article is believed to be true and accurate on the date of its going to press, neither UniCollaboration nor University of Groningen Press can accept any legal responsibility for any errors or omissions. Additionally, the publisher makes no warranty, expressed or implied, with respect to the material contained herein. While University of Groningen Press is committed to publishing works of integrity, the words are the authors' alone.

Trademark notice. Product or corporate names may be trademarks or registered trademarks, and are used only for identification and explanation without intent to infringe.

Copyrighted material. Every effort has been made by the editorial team to trace copyright holders and to obtain their permission for the use of copyrighted material in this article. In the event of errors or omissions, please notify the publisher of any corrections that will need to by incorporated in future editions of this article.

Typeset by Research-publishing.net (https://research-publishing.net)

Noto fonts are open source. All Noto fonts are published under the SIL Open Font License, Version 1.1. Noto is a trademark of Google Inc. (https://www.google.com/get/noto/).

ISSN: 2647-4832 (online only)

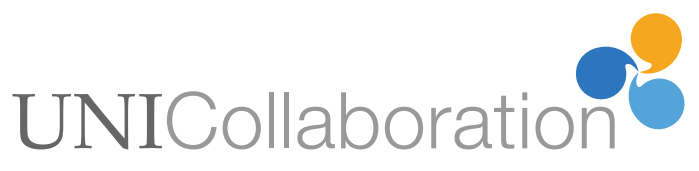

